\title{
Estudo farmacognóstico comparativo das folhas de Davilla elliptica A. St.-Hil. e D. rugosa Poir., Dilleniaceae
}

\author{
Rose Lisieux R. Paiva Jácome, ${ }^{* 1}$ Virgínia Del Carmen Oliveira, ${ }^{2}$ Michael Alberto Teixeira e \\ Oliveira, ${ }^{1}$ Maria Cecília Ferreira Mariano, ${ }^{1}$ Alaide Braga de Oliveira ${ }^{1}$
}

\author{
${ }^{1}$ Departamento de Produtos Farmacêuticos da Faculdade de Farmácia, Universidade Federal de Minas Gerais, \\ Av. Antonio Carlos, 6627, Pampulha, 31270-010 Belo Horizonte-MG, Brasil, \\ ${ }^{2}$ Laboratório de Microscopia de Produtos, Fundação Ezequiel Dias, R. Conde Pereira Carneiro, 80, 30510-010 \\ Belo Horizonte-MG, Brasil.
}

\begin{abstract}
RESUMO: As características farmacognósticas das folhas de Davilla elliptica A. St.-Hil. e D. rugosa Poir., Dilleniaceae, foram determinadas com objetivo de auxiliar na identificação taxonômica e no controle de qualidade das drogas vegetais e de produtos fitoterápicos. A espécie D. elliptica é um arbusto ereto, que ocorre naturalmente no cerrado e $D$. rugosa é um trepadeira lenhosa de beira de mata. Ambas são conhecidas popularmente como lixeirinha, sambaibinha e cipócaboclo, empregadas na medicina tradicional como antiinflamatória e antiúlcera. As características microscópicas observadas em $D$. rugosa tais como tricomas estrelados e esclereídes no mesofilo e em $D$. elliptica de idioblastos contendo mucilagem e endoderme, são parâmetros que poderão ser utilizados na diferenciação das espécies. Os teores obtidos nos ensaios de pureza e nos doseamentos de taninos $(9,4 \%$ e $7,2 \%)$, flavonoides $(0,46 \%$ e $0,9 \%)$ e mucilagens $(2,2 \%$ e $4,1 \%)$ de ambas as espécies, podem contribuir no controle de qualidade das drogas vegetais uma vez que são usadas indistintamente na produção de fitoterápicos.
\end{abstract}

Unitermos: Davilla elliptica, D. rugosa, caracterização farmacognóstica, controle de qualidade.

\begin{abstract}
Comparative pharmacognostic study of leaves of Davilla elliptica A. St.-Hil. e D. rugosa Poir., Dilleniaceae. The characters pharmacognostics of leaves of Davilla elliptica St. Hil. and Davilla rugosa Poir. of Dilleniaceae family were determinated for aiming in taxonomic and quality control of vegetable drugs and phytotherapic produtcs. The specie of D. elliptica is an erect shrub, that occurs naturally in cerrado and D. rugosa is a scandent shrub of forest edge. Both are populary known as "lixeirinha”, "sambaibinha” and “cipó-caboclo” and used in popular medicine as anti-inflammatory and antiulcer. The microscopic characteristics observed like strellate trichomes and sclereids in the mesophyll in D. rugosa and the idioblasts with mucilage and endodermis in $D$. elliptica are parameter that will be used to differentiate the species. The content obtained in tests of purity and the tannins $(9.4 \%$ and $7.2 \%)$, flavonoids $(0.46 \%$ and $0.9 \%)$ and mucilage $(2.2 \%$ and $4.1 \%$ ) of both species help in quality control of vegetable drugs since they are indistinctly used in production of phytotherapics.
\end{abstract}

Keywords: Davilla elliptica, D. rugosa, pharmacognostic characterization, quality control.

\section{INTRODUÇÃO}

No Brasil a família Dilleniaceae está representada por cinco gêneros e aproximadamente cinquenta espécies (Joly, 1998; Souza \& Lorenzi, 2005) e caracteriza-se pela presença de agliconas flavônicas muitas vezes na forma de glicosídeos (Gurni \& Kubitzki, 1981; Gurni et al., 1981; David et al. 2006; Rinaldo et al. 2006). Várias espécies do gênero Davilla são conhecidas na medicina popular, com diversas indicações terapêuticas, dentre elas destacase a utilização como antiinflamatória e antiúlcera gástrica (Correa, 1931; Silva, 1989; Rodrigues \& Carvalho, 2001).
As espécies D. rugosa e D. elliptica são freqüentemente confundidas e usadas indistintamente na produção de medicamentos. Um estudo comparativo entre as duas espécies tem como objetivo auxiliar na diferenciação e no controle de qualidade das drogas vegetais.

D. elliptica é uma planta arbórea, que ocorre naturalmente no cerrado brasileiro (Correa, 1978; Aymard, 2002), conhecida popularmente como lixeirinha, lixeira e sambaibinha. É empregada na medicina tradicional como adstringente, tônico, laxativo, diurético (Oliveira \& Castro, 1966; Rodrigues \& Carvalho, 2001). Estudos realizados com extratos de $D$. elliptica mostraram efeito 
imunoestimulatório em ratos, o que sugere um benefício no aumento da imunidade contra doenças infecciosas e propriedades antimicrobianas (Michelin et al., 2005; Carlos et al., 2005). O flavonoide miricetina-3-O- $\beta$-galactosídeo isolado do extrato etanólico de folhas apresentou atividade antinociceptiva e antiinflamatória reforçando o uso popular da espécie (Campos, 2006; Azevedo et al., 2007).

D. rugosa é uma trepadeira lenhosa de folhas ásperas nas duas faces, conhecida como folha de lixa, cipócarijó, cipó-caboclo, comum em bordas de florestas, com distribuição geográfica bem ampla no Brasil (Hyakutake, 1969; Souza \& Lorenzi, 2005), utilizada como analgésica, vasoconstritora e antiúlcera, útil no tratamento das hemorróidas, varizes e orquites (Correa, 1931; Silva, 1989). As descrições macro e microscópicas encontramse na Farmacopéia Brasileira (1926). Investigações farmacológicas detectaram atividade anti-ulcerogênica e efeito estimulante dos extratos hidroalcoólicos do caule de $D$. rugosa em modelos animais (Guaraldo et al., 2000, 2001).

\section{MATERIAL E MÉTODOS}

\section{Material vegetal}

Para a realização dos estudos foram coletadas folhas de Davilla elliptica A. St.-Hil. numa área de cerrado, no bairro Samambaia do Município de Juatuba (coordenadas 0573008, 7790200, $771 \mathrm{~m}$ ), em dezembro de 2004, e de D. rugosa em regiões de mata na Estação Ecológica de Peti em Santa Bárbara (coordenadas 0671223 , 7799870, $781 \mathrm{~m}$ ), em agosto de 2005, ambas em Minas Gerais. As exsicatas foram incorporadas ao acervo do Herbário do Departamento de Botânica da UFMG, sob os números BHCB 47556 e BHCB 71689, respectivamente.

\section{Análise microscópica}

Para estudos em microscopia de luz, as amostras foram preparadas segundo dois procedimentos: seccionamento do material à mão livre, com auxílio de lâminas de cortar e inclusão em Paraplast ${ }^{\circledR}$ e historresina (Kraus \& Arduin, 1997) para seccionamento em micrótomo rotativo Leica Jung Biocut ${ }^{\circledR}$ (mod. 2035). Foram realizadas seções transversais e longitudinais da região mediana da lâmina foliar e paradérmicas das faces adaxial e abaxial da folha. Amostras das folhas das duas espécies foram fixadas em FAA 70 (Johansen, 1940) e armazenadas em álcool $70 \%$. Os cortes foram corados com azul de astra e fucsina (Roeser, 1972) e azul de toluidina 0,05\% (O’Brien et al., 1965). A epiderme foi obtida através da dissociação de fragmentos vegetais utilizando-se mistura de Jeffrey (Johansen, 1940), diafanizada com hipoclorito de sódio a $1 \%$ (Bersier \& Bocquet, 1960), coradas com safranina e as lâminas foram montadas em gelatina glicerinada.

Os testes histoquímicos foram efetuados utilizando material fresco. Os cortes obtidos foram submetidos aos seguintes reagentes: floroglucina clorídrica para evidenciar lignina (Johansen, 1940); Sudan IV (Foster, 1949) para detecção de lipídios, cutina e suberina; tinta nanquim para evidenciar mucilagem (F. Bras IV, 2002) e vermelho de rutênio para substâncias pécticas (Chamberlain, 1932).

As fotomicrografias foram obtidas com microscópio Olympus CX 31, acoplado a uma câmara fotográfica Olympus SC-35.

\section{Determinação do teor de extrativos e dos ensaios de pureza}

As folhas de ambas as espécies foram secas em estufa a $40{ }^{\circ} \mathrm{C}$, pulverizadas em moinho de faca e tamisadas em tamis 20. Dez gramas do pó de cada amostra foram submetidos ao processo de extração em aparelho de Soxhlet, utilizando a série de solventes: $n$-hexano, etanol e solução hidroalcoólica a $70 \%$. O teor de extrativos foi determinado pela média de três análises. A determinação dos teores de água, de cinzas totais, insolúveis em ácido também foi realizada em triplicata (F. Bras. IV, 1988).

\section{Caracterização fitoquímica e doseamentos}

As classes de metabólitos secundários foram detectadas para os três extratos das duas espécies por cromatografia em camada delgada (CCD) analítica em gel de sílica $\mathrm{G}$ (Wagner et al., 1984). Com base na prospecção fitoquímica foram realizadas as determinações quantitativas de taninos e de flavonoides por espectrometria no visível, utilizando reagente de Folin-Denis e solução metanólica de cloreto de alumínio a $2 \%(\mathrm{p} / \mathrm{V})$. Com base na análise histoquímica foi determinado o teor de mucilagens pelo índice de intumescimento. As determinações também foram realizadas em triplicata (F. Bras IV, 2002).

\section{RESULTADOS}

\section{Descrição macroscópica}

Os indivíduos de $D$. rugosa apresentam-se como trepadeiras lenhosas em beira de mata (Figura 2) e os indivíduos de D. elliptica ocorrem no cerrado como árvores, arbustos e subarbustos muito ramificados de 0,6 $\mathrm{cm}$ até $3 \mathrm{~m}$ de altura (Figura 1 ).

As folhas de ambas as espécies são alternas, pecioladas, sem estípulas, de 4 a $8 \mathrm{~cm}$ de comprimento e 3 a $4 \mathrm{~cm}$ de largura, oblongas, ovais ou elípticas, coriáceas e ásperas. $D$. rugosa possui margens proeminentemente serreadas e ambas as faces ásperas (Figura 2), enquanto que $D$. elliptica apresenta margens sinuosas, levemente serreadas ásperas na face superior e pubescentes na face inferior (Figura 1). O pecíolo de ambas as espécies mede 1 a $1,5 \mathrm{~cm}$ de comprimento e é canaliculado. 

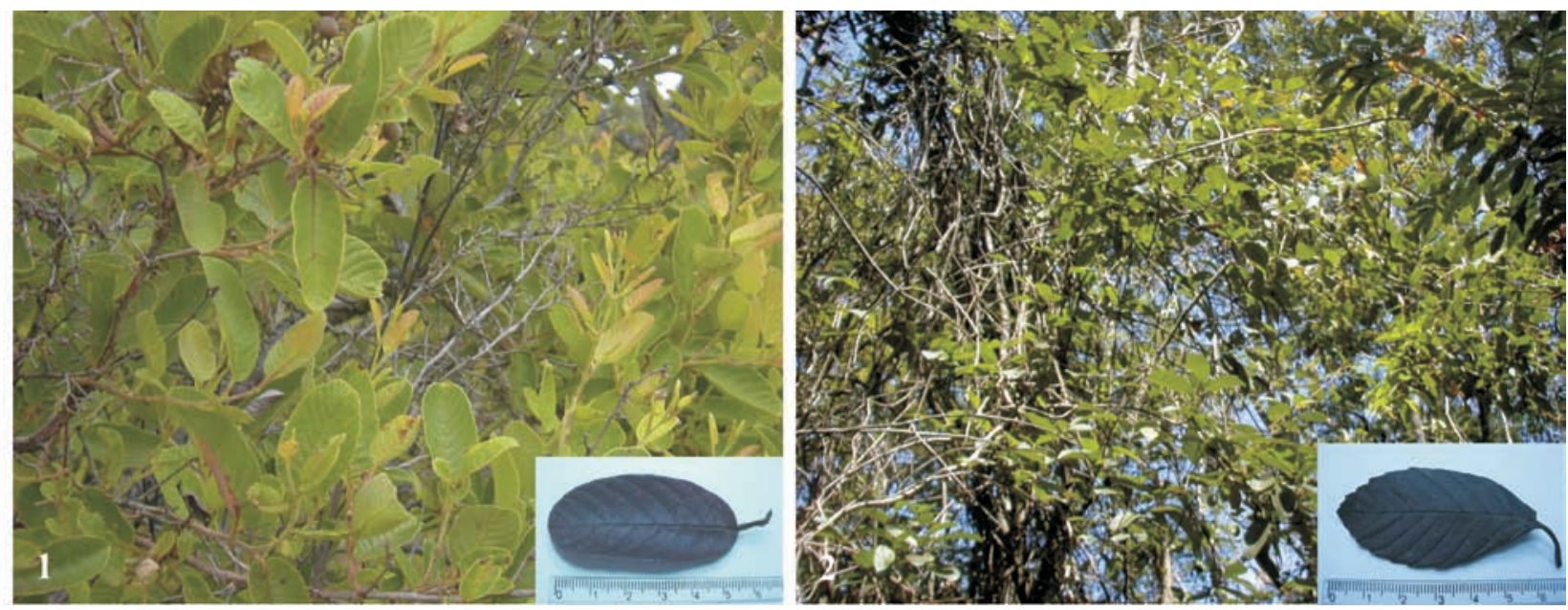

Figuras 1-2. Hábitos e detalhe da folha. 1. Arbusto de D. elliptica St. Hill. 2. Trepadeira lenhosa de D. rugosa Poir.

\section{Descrição microscópica de $D$. elliptica e $D$. rugosa}

As folhas destas espécies apresentam características anatômicas semelhantes. A epiderme adaxial das duas espécies em vista frontal é formada de células poligonais de paredes sinuosas (Figuras $3 \mathrm{~A} \mathrm{e} 4 \mathrm{~A}$ ) e na epiderme abaxial células com paredes menos sinuosas (Figuras 3D e 4C). Ambas as espécies são hipoestomáticas com os estômatos entre anomocíticos e paracíticos (Figuras 3B, 3D e 4C). Em D. elliptica os tricomas tectores são unicelulares em ambas as faces, circundados em geral por seis a oito células diferenciadas (Figuras 3A, 3B e 3C) e em D. rugosa os tricomas na epiderme abaxial são estrelados (Figura 4B).

Cortes transversais da lâmina foliar revelam a epiderme uniestratificada em ambas espécies, formada de células retangulares intercaladas pela inserção dos tricomas tectores (Figuras 5A e 6A). O mesofilo é dorsiventral com duas camadas de parênquima paliçádico em $D$. elliptica, sendo a segunda interrompida eventualmente por idioblastos alguns possuindo ráfides de oxalato de cálcio e outros, na sua grande maioria, contendo mucilagem (Figura 5A). O parênquima esponjoso é formado por um conjunto de células alongadas de braços curtos com a presença também de idioblastos (Figura 5A). Em D. rugosa o mesofilo possui uma camada de parênquima paliçádico interrompido por esclereídes e idioblastos com ráfides (Figura 6A) sendo raro a presença de mucilagem. Os esclereídes são projeções da base dos tricomas no mesofilo. $\mathrm{O}$ parênquima esponjoso possui numerosos espaços intercelulares (Figuras 6A e 6B).

A margem da folha em ambas as espécies é formada por colênquima e apresenta um formato em ponta fechando gradativamente o limbo foliar (Figuras $5 \mathrm{~B}$ e 6B).

O sistema vascular do limbo é representado pelas nervuras principais (Figura $5 \mathrm{C}$ e $6 \mathrm{C}$ ) e secundárias (Figura $5 \mathrm{~A}$ e $6 \mathrm{~A}$ ). A nervura principal é formada por um anel de
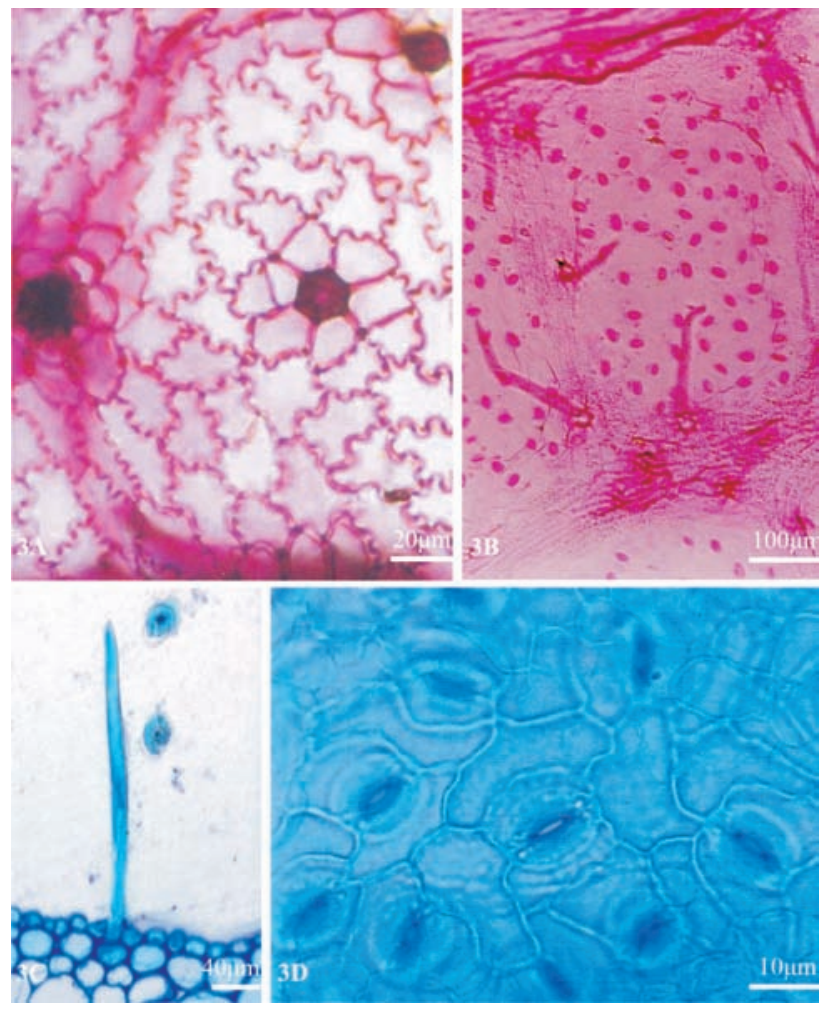

Figura 3. Folha de D. elliptica. A. Epiderme adaxial em vista frontal com base de tricoma. B. Epiderme abaxial com tricomas tectores e estômatos em vista frontal. C. Em secção transversal, detalhe do tricoma tector. D. Estômatos paracíticos em vista frontal.

feixes vasculares circundado por fibras esclerênquimáticas. O colênquima apresenta-se como um maciço de células em contato com a epiderme superior e com duas a três fileiras de células na região adjacente à epiderme inferior (Figura $5 \mathrm{C}$ e $6 \mathrm{C})$.

Em D. elliptica externamente as fibras, observase uma endoderme que se apresenta com células de paredes 
finas e alongadas e um parênquima cortical com idioblastos contendo mucilagem (Figura $5 \mathrm{C}$ ). Em D. rugosa não se observa endoderme nem idioblastos contendo mucilagens (Figura 6C).
O pecíolo é côncavo-convexo com duas projeções laterais proeminentes em ambas espécies (Figuras 5D e 6D), sendo que a região cortical de D. elliptica possui idioblastos com mucilagem (Figuras 5E e 5F).
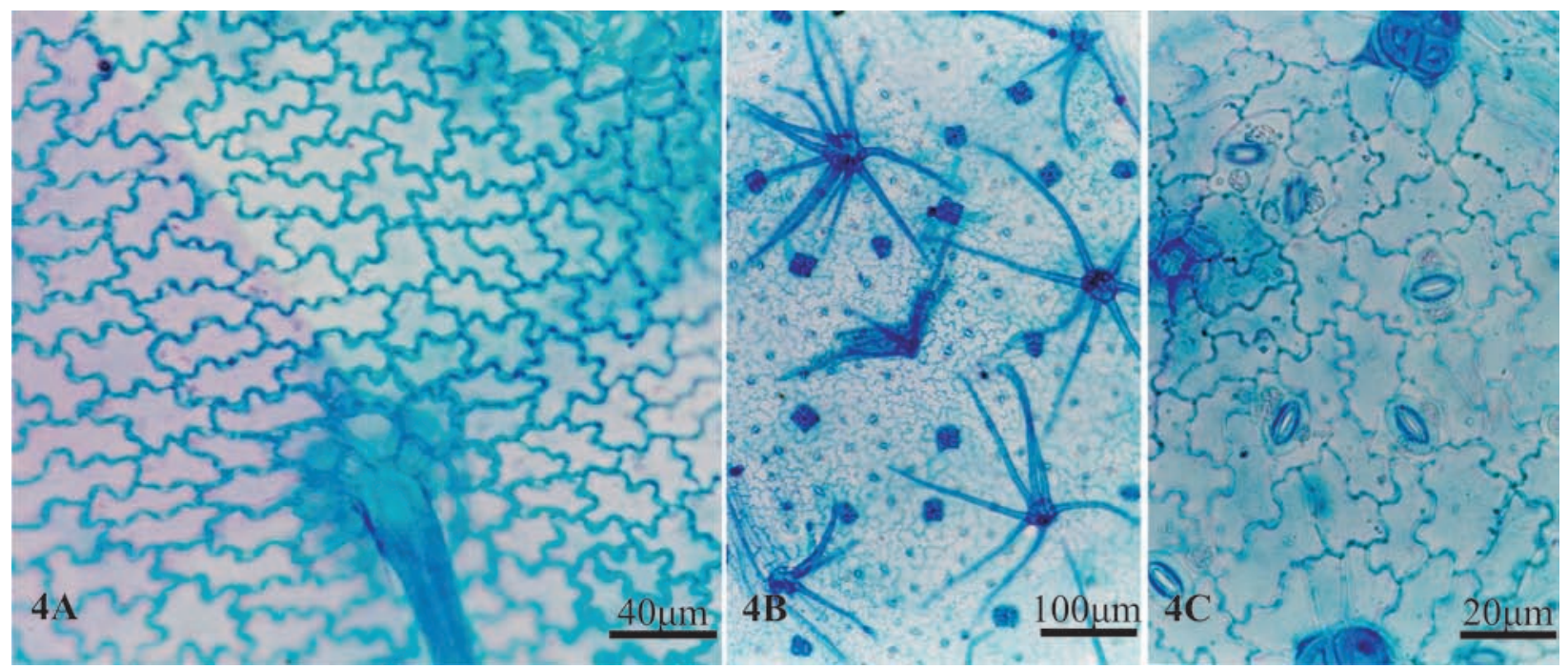

Figura 4. Folha de D. rugosa em vista frontal A. Epiderme adaxial com células poligonais e sinuosas e base de tricoma unicelular. B. Epiderme abaxial com tricomas estrelados. C. Epiderme adaxial com estômatos anomocíticos.
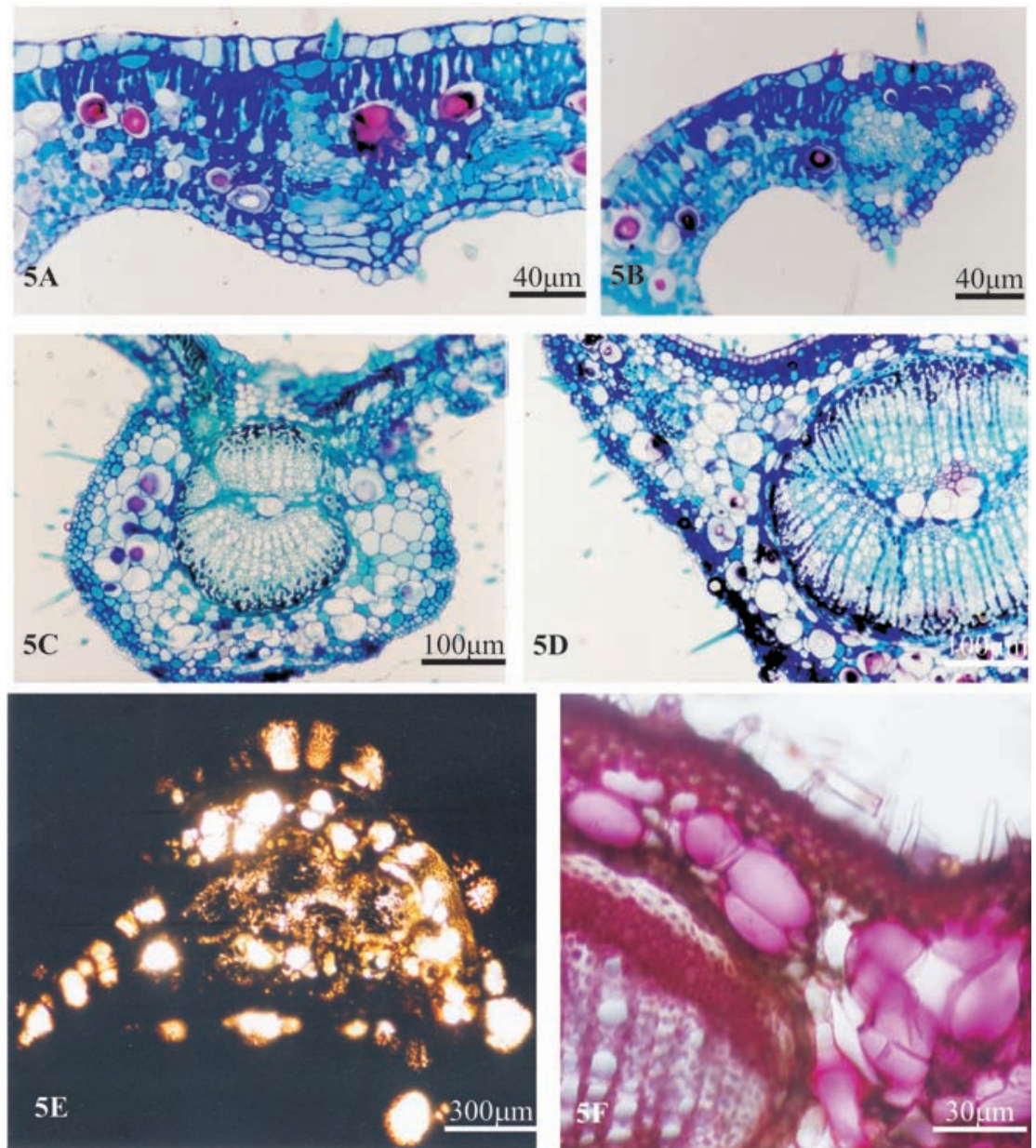

Figura 5. Seções transversais da folha de D. elliptica. A. Mesofilo constituído por parênquima paliçádico e esponjoso com idioblastos. B. Bordo da lâmina foliar. C. Nervura principal com idioblastos na região cortical. D. Pecíolo com cilindro vascular central. E. Pecíolo com mucilagem evidenciada pelo nanquim. F. Pecíolo com compostos pécticos evidenciados pelo vermelho de rutênico. 


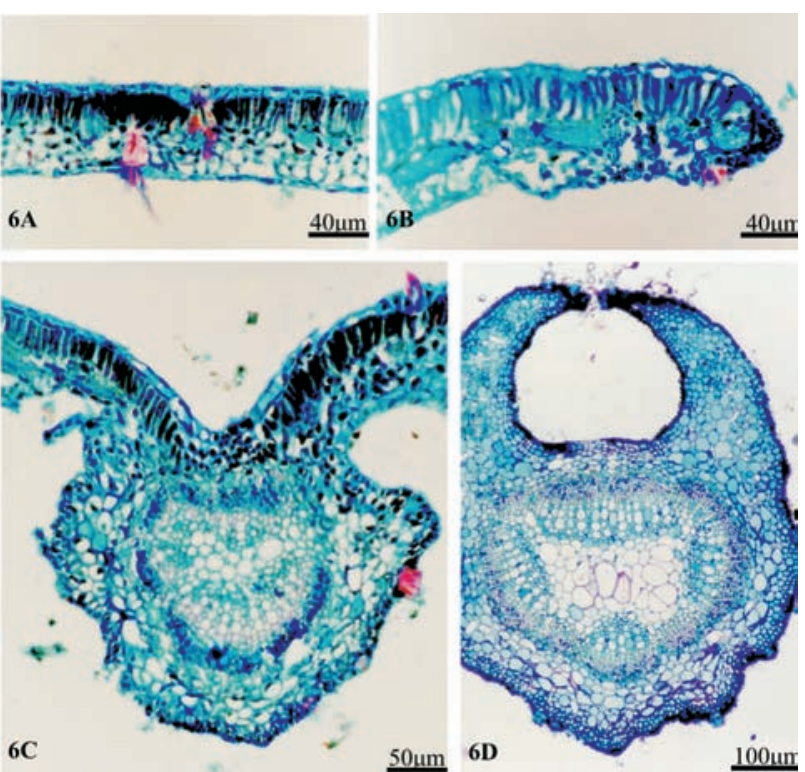

Figura 6. D. rugosa em seção transversal. A. Mesofilo com parênquima paliçádico e esponjoso. B. Bordo foliar. C. Nervura com cilindro vascular. D. Pecíolo com cilindro vascular.

\section{Determinação do teor de extrativos e dos ensaios de pureza}

Os teores de perda por dessecação, cinzas totais, cinzas insolúveis em ácido e os doseamentos de flavonoides, taninos e mucilagens determinados em $D$. elliptica e D. rugosa estão representados na Tabela 1.

A caracterização dos grupos químicos nas duas espécies detectou a presença de esteróides e/ou triterpenos, cumarinas, heterosídeos flavônicos, polifenóis, taninos e saponinas. Para detecção de flavonoides em CCD foi utilizada como fase móvel: acetato de etila/ácido fórmico/ ácido acético/água (100:11:11:27) e como revelador o cloreto de alumínio a $5 \%$ em etanol e visualização em lâmpada UV em $356 \mathrm{~nm}$. Em D. elliptica foi possível visualizar no extrato etanólico 8 flavonoides com os seguintes $\mathrm{R}_{\mathrm{f}} 0,26 ; 0,32 ; 0,42 ; 0,50 ; 0,58 ; 0,66 ; 0,72$ e 0,85 e em $D$. rugosa no extrato etanólico três flavonoides $(0,35$; $0,53$ e 0,64$)$ e no hidroetanólico 6 flavonoides com os seguintes $\mathrm{R}_{\mathrm{f}} 0,34 ; 0,53 ; 0,60 ; 0,65 ; 0,70 ; 0,82$ (Figura 7).

\section{DISCUSSÃO}

O trabalho revelou que as espécies estudadas apresentam características comuns da família Dilleniaceae como: folhas hipoestomásticas, dorsiventrais, com presença de tricomas tectores unicelulares e ausência de tricomas glandulares (Metcalfe \& Chalk, 1965), assim como a ocorrência de sílica na parede celular (Solereder, 1908).

O mesofilo dorsiventral descrito no presente estudo para ambas as espécies foi corroborado por Silva (1989) e Hyakutake (1969) para D. rugosa, enquanto

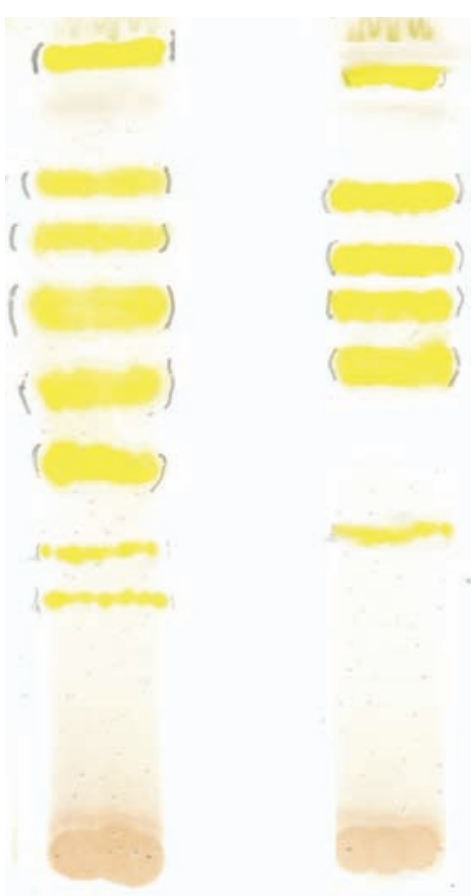

Figura 7. Perfil cromatográfico, obtido por CCD, dos extratos etanólico de $D$. elliptica e hidroetanólico de $D$. rugosa. Eluente: acetato de etila/ácido fórmico/ácido acético/água (100:11:11:27). Revelador: cloreto de alumínio a 5\% em etanol.

Tabela 1. Determinação do teor de extrativos, ensaios de pureza e doseamentos de flavonoides, taninos e mucilagens em $D$. elliptica e D. rugosa (\%), $\mathrm{n}=3$

\begin{tabular}{lcc}
\hline & D. elliptica & D. rugosa \\
\hline Extrato hexânico & $0,19+0,2$ & $0,573+0,007$ \\
Extrato etanólico & $1,73+0,05$ & $2,09+0,08$ \\
Extrato hidroetanólico $(70 \%)$ & $0,47+0,04$ & $0,63+0,01$ \\
Perda por dessecação & $9,72+0,09$ & $2,6+0,1$ \\
Cinzas totais & $7,6+0,3$ & $11,0+0,2$ \\
Cinzas insolúveis & $3,5+0,4$ & $5,4+0,5$ \\
Teor de polifenóis & $15,52+0,03$ & $11,7+0,5$ \\
Teor de taninos & $7,2+0,2$ & $9,4+0,4$ \\
Teor de flavonoides & $0,9+0,2$ & $0,46+0,02$ \\
Índice de intumescência & $4,1+0,4$ & $2,2+0,3$ \\
\hline
\end{tabular}

para D. elliptica foi descrito como isolateral por Oliveira \& Castro (2002) e Soares et al. 2005. As observações diferentes podem ser devido ao fato de que o parênquima paliçádico e esponjoso não estão nitidamente diferenciados em $D$. elliptica. A endoderme envolvendo os tecidos vasculares observada na folha de $D$. elliptica e também descrita por Oliveira \& Castro (2002) é uma característica farmacognóstica importante na diferenciação das espécies. A descrição macro e microscópica de $D$. rugosa da Farmacopéia Brasileira (1926) coincide mais com aquela de D. elliptica, mostrando a dificuldade de diferenciação destas espécies. 
A determinação dos ensaios de pureza constitui referência de qualidade e caracterização da matéria prima vegetal. Ambas as espécies apresentam alto teor de cinzas insolúveis em ácido o que corrobora com a presença de sílica nas paredes celulares das folhas da família Dilleniaceae (Barroso et al., 1978; Oliveira \& Castro, 2002; Soares et al., 2005). Assim, comparando-se os resultados obtidos na determinação desse teor em $D$. elliptica $(3,46 \%)$ com os de $D$. rugosa $(5,40 \%)$, pode-se inferir que o maior teor de sílica em $D$. rugosa esteja relacionado não só ao maior número de tricomas estrelados como também aos esclereídes presentes no mesofilo.

A perda por dessecação em $D$. elliptica foi maior do que em $D$. rugosa $(9,7$ e $2,6 \%)$ o que se deve a maior quantidade de idioblastos com mucilagens em $D$. elliptica, importante característica farmacognóstica, descrita pela primeira vez neste trabalho, para diferenciar as duas espécies. Também o teor de mucilagem desta espécie foi quase o dobro em relação a $D$. rugosa $(4,10 \%$ e $2,17 \%)$.

$\mathrm{O}$ número de flavonoides em $\mathrm{CCD}$ e o teor por espectrofotometria foi maior nas folhas de $D$. elliptica $(0,91 \%)$, enquanto o teor de taninos foi maior nas folhas de $D$. rugosa $(9,4 \%)$. O teor de taninos e flavonóides determinados nas folhas de $D$. elliptica neste trabalho $(7,20 \%$ e $0,91 \%)$, coletadas na época chuvosa, foi menor que aquele encontrado por Soares et al. (2005) $(9,89$ a $13,96 \%$ e 1,20 a $1,48 \%$ ) em coletas realizadas em abril e julho, indicando a variação sazonal dos grupos de metabólitos secundários. Entretanto faz-se necessário uma avaliação com um maior número de amostras para verificação sazonal do teor de metabólitos secundários. Tanto o teor de taninos quanto de flavonoides para as duas espécies pode ser considerado grande $(7,20 \%, 9,40$ $\%$ e $0,91 \% ; 0,46 \%$ ) quando comparado com outras drogas farmacopêicas como Stryphnodendron adstringens (8\%) e Psidium guajava (5,5\%) para taninos e Baccharis trimera $(0,5 \%)$ e Calendula officinalis $(0,4 \%)$ para flavonoides.

\section{CONCLUSÃO}

As características farmacognósticas observadas, neste estudo, como tricomas estrelados e esclereídes no mesofilo em $D$. rugosa e de idioblastos contendo mucilagem e endoderme em $D$. elliptica, assim como os teores obtidos dos ensaios de pureza e dos doseamentos de flavonóides, taninos e mucilagens fornecerão parâmetros que poderão ser utilizados no controle de qualidade da droga vegetal de ambas as espécies.

Como D. elliptica possui o teor de mucilagens e de flavonoides maior que $D$. rugosa, compostos estes com propriedades farmacológicas importantes (Harborne \& Williams, 2000; Cunha, 2005, Campos, 2006), faz-se necessário estudos complementares e consequentemente sua utilização na indústria farmacêutica. Os valores encontrados para $D$. rugosa nos ensaios de pureza e nos doseamentos estão pela primeira vez descritos neste trabalho.

\section{AGRADECIMENTOS}

À FAPEMIG pelo auxílio financeiro e pela concessão de bolsa de iniciação científica a MATO.

\section{REFERÊNCIAS}

Azevedo AO, Campos JJ, Galdino GS, Duarte IDG, Braga FC, Peres AC 2007. Antinociceptive effect from Davilla elliptica hydrooalcoholic extract. J Ethnopharmacol 113: 354-356.

Aymard GAC 2002. A new species of Davilla (Dilleniaceae) amongst the flora of São Paulo, Brazil. Acta Bot Ven 25: 153-159.

Barroso GM, Guimarães EF, Ichaso CLF, Costa CG, Peixoto AL 1978. Sistemática das Angiospermas do Brasil. São Paulo: Ed. da Universidade de São Paulo, v.1.

Bersier JD, Bocquet D 1960. Les méthodes d'éclaircissement em vascularisation et em morphogénie végétales comparées. Arch Scienc 13: 555-566.

Campos JJ 2006. Estudo fitoquímico e das atividades antiinflamatória e antinociceptiva de Davilla elliptica St. Hill. Belo Horizonte, 147p. Dissertação de mestrado - Faculdade de Farmácia, Universidade Federal de Minas Gerais.

Carlos IZ, Lopes FCM, Benzatti FP, Carli CBA, Marques MF, Jordão Junior CM, Rinaldo D, Calvo TR, Santos LC, Vilegas W 2005. Ação do extrato metanólico e etanólico de Davilla elliptica St. Hill. (Dilleniaceae) na resposta imune. Rev Bras Farmacogn 15: 44-45.

Chamberlain CJ 1932. Methods in plant histology. Chicago: The University of Chicago Press.

Correa PM 1931. Dicionário das plantas úteis do Brasil e das exóticas cultivadas. Rio de Janeiro: Imprensa Nacional, v. II.

Correa MP 1978. Dicionário das plantas úteis do Brasil e das exóticas cultivadas. Rio de Janeiro: Imprensa Nacional, v. VI.

Cunha AP 2005. Farmacognosia e fitoquímica. Lisboa: Fundação Calouste Gulbenkian.

David JM, Souza JC, Guedes MLS, David JP 2006. Estudo fitoquímico de Davilla rugosa: flavonóides e terpenóides. Rev Bras Farmacogn 16: 105-108.

Farmacopéia dos Estados Unidos do Brasil 1926. $1^{\text {a }}$ Ed. São Paulo: Editora Nacional.

Farmacopéia Brasileira 1988. $4^{\mathrm{a}}$ Ed. São Paulo: Atheneu.

Farmacopéia Brasileira 2002, $4^{\mathrm{a}}$ ed. São Paulo: Atheneu.

Foster AS 1949. Practical plant anatomy. Princenton: D van Nostrand Company Inc.

Guaraldo L, Chagas DA, Konno AC, Korn GP, Pfiffer T, Nasello AG 2000. Hydroalcoholic extract and fractions of Davilla rugosa Poiret: effects on spontaneous motor activity and elevated plus-maze behavior. J Ethnopharmacol 72: 6167.

Guaraldo L, Sertie JAA, Bacchi EM 2001. Antiulcer action of the hydroalcoholic extract and fractions of Davilla rugosa Poiret in the rat. J Ethnopharmacol 76: 191-195.

Gurni AA, Konig WA, Kubitzki K 1981. Flavonoid glycosides and sulphates from the Dilleniaceae. Phytochemistry 20: 1057-1059.

Gurni AA, Kubitzki K 1981. Flavonoid chemistry and systematics of the Dilleniaceae. Biochem Syst Ecol 9: 109-114. 
Harborne JB, Williams CA 2000. Advances in flavonoid research since 1992. Phytochemistry 55: 482-504.

Hyakutake S 1969. Contribuição para o estudo botânico da espécie Davilla rugosa Poiret var. rugosa, Dilleniaceae. Rev Fac Farm Bioquím 7: 285-293.

Johansen DA 1940. Plant microtechnique. New York: McGrawHill Book Co. Inc.

Joly AB 1998. Botânica: introdução a taxonomia vegetal. São Paulo: Companhia Editora Nacional, 12a ed.

Kraus JE, Arduin M 1997 Manual básico de métodos em morfologia vegetal. Seropédica: EDUR.

Metcalfe CR, Chalk L 1965. Anatomy of the Dicotyledons. Oxford: Clarendon Press, v.1.

Michelin DC, Iha SM, Rinaldo D, Sannomiy AM, Santos LC, Vilegas W, Salgado HRN 2005. Antimicrobial activity of Davilla elliptica St. Hil. (Dilleniaceae). Rev Bras Farmacogn 15: 209-211.

O'Brien TP, Feder N, McCully ME 1965. Polychromatic staining of plant cell walls by toluidine blue O. Protoplasma 59: 368-373.

Oliveira LA, Castro NM 2002. Ocorrência de sílica nas folhas de Curatella americana L. e Davilla elliptica St. Hil. Ann Acad Bras Cien (Supl) 38: 159-170.

Rinaldo D, Silva MA, Rodrigues CM, Sannomiya TRM, Santos LC, Vilegas W, Hiruma-Lima HK, Brito ARMS 2006. Preparative separation of flavonoids from the medicinal plant $D$. elliptica St. Hill. by high-speed counter-current chromatography. Quim Nova 29: 1-6.

Roeser KR 1972. Die nadel der schwarzkiefer. Massenprodukt und kunstwerk der natur. Mikrokosmos 61: 33-36.

Rodrigues VEG, Carvalho DA 2001. Levantamento etnobotânico de plantas medicinais do domínio do cerrado na região do alto Rio Grande - Minas Gerais. Cienc Agrotec 25: 102-123.

Silva RAD 1989. Plantas medicinais brasileiras. Estudo botânico e farmacognóstico. Rev Bras Farm 70: 36-38.

Soares ML, Rezende MH, Ferreira HD, Figueiredo ADL, Bustamante KGL, Bara MTF, Paula JR 2005. Caracterização farmacognóstica de folhas de Davilla elliptica St. Hil. (Dilleniaceae). Rev Bras Farmacogn 15: 352-360.

Solereder H. 1908. Systematic anatomy of the Dicotyledons. Oxford: Clarendon Press.

Souza VC, Lorenzi H 2005. Botânica sistemática: guia ilustrado para identificação das famílias de Angiospermas da flora brasileira, baseado em APG II. Nova Odessa, SP: Instituto Plantarum.

Wagner H, Bladt S, Zgainski EM 1984. Plant Drug Analysis: A Thin Layer Chromatography Atlas. Berlin: SpringerVerlag. 